\title{
Ensino de Mecânica Quântica na licenciatura em Física por meio da História e Filosofia da Ciência ${ }^{+*}$
}

\author{
Rafaelle da Silva Souza ${ }^{1}$ \\ Instituto Federal de Educação, Ciência e Tecnologia da Bahia \\ Seabra - BA \\ Ileana Maria Grecal \\ Universidad de Burgos \\ Burgos - Espanha \\ Indianara Silva ${ }^{1}$ \\ Universidade Estadual de Feira de Santana \\ Feira de Santana - BA \\ Elder Sales Teixeira ${ }^{1}$ \\ Universidade Estadual de Feira de Santana \\ Feira de Santana - BA
}

\section{Resumo}

Neste artigo são analisados os resultados da aplicação de uma proposta didática no contexto de ensino da Mecânica Quântica (MQ) baseada na História e Filosofia da Ciência (HFC) implementada no curso de licenciatura em Física. É discutido do planejamento às atividades de aprendizagem observando como essas potencializam ou limitam a concretização da compreensão histórico-conceitual da Teoria Quântica. Foi possível concluir, através de observação, gravação de áudio e vídeo e documento (atividades individuais), que a proposta conseguiu conduzir as ações que envolvem a prática docente, desde o conteúdo especifico até o planejamento do processo de transposição didática. Entre as contribuições da pesquisa, o uso da HFC como o eixo condutor do ensino promoveu a contextualização dos conteúdos no próprio processo de sua produção, criando condições para que os estudantes aprendam a $M Q$ experimentando a curiosidade e a autonomia na construção de seu aprendizado. Os resultados também apontam que existem importantes

\footnotetext{
${ }^{+}$Teaching Quantum Mechanics in degree in Physics through the History and Philosophy of Science

* Recebido: 22 de maio de 2020. Aceito: 9 de março de 2021.

${ }^{1}$ E-mails: rafaellessouza@gmail.com; imgreca@ubu.es; indianara.slima@gmail.com; eldersate@gmail.com
} 
cuidados a serem tomados quando se propõe metodologias inovadoras para o processo de ensino-aprendizagem.

Palavras-chave: História e Filosofia da Ciência; Mecânica Quântica; Licenciatura em Física.

\begin{abstract}
This article analyzes the results of the application of a didactic proposal in the context of teaching Quantum Mechanics (QM) based on the History and Philosophy of Science (HPS) implemented in the undergraduate degree in physics. It's discussed from planning to learning activities observing how these potentialize or limit the realization of the historical-conceptual understanding of Quantum Theory. It was possible to conclude, through observation, audio and video recording and document (individual activities), that the proposal was able to conduct the actions involving the teaching practice, from the specific content to the planning of the didactic transposition process. Among the contributions of the research, the use of HFC as the driving axis of teaching promoted the contextualization of the contents in the very process of its production, creating conditions for students to learn $M Q$ by experiencing curiosity and autonomy in the construction of their learning. The results also indicate that there are important precautions to be taken when proposing innovative methodologies for the teachinglearning process.
\end{abstract}

Keywords: History and Philosophy of Science; Quantum Mechanics; Undergraduate Degree in Physics.

\title{
I. Introdução
}

A Mecânica Quântica (MQ) é considerada uma área de estudo complexa tanto em seu aspecto formal quanto conceitual. Os próprios espaços de formação, nos quais essa percepção poderia ser evitada, muitas vezes acabam reforçando-a (CUESTA, 2018). Isso ocorre, especialmente, a partir de abordagens centradas em formulações matemáticas com raros momentos de associação do formalismo com os aspectos conceituais da teoria. Segundo Johansson et al. (2016), a supervalorização de procedimentos matemáticos acaba promovendo um distanciamento dos seus conceitos, interpretações e dos resultados experimentais.

Extensas revisões de literatura sobre o ensino de MQ e do seu formalismo revelam a necessidade da adoção de metodologias inovadoras como alternativas para suportar as 
mudanças dos processos de ensinar e aprender, alinhadas às novas exigências das regulamentações educacionais (SOUZA et al., 2021). O esperado é que o recém-formado, uma vez atuando no Ensino Médio, tenha segurança e sinta-se capacitado de discutir tópicos da MQ em sala de aula.

Em razão desses aspectos, propõe-se ensinar MQ por meio da História e Filosofia da Ciência (HFC) no contexto da licenciatura em Física, de maneira a favorecer a aprendizagem. Nesse artigo é, portanto, apresentado os resultados do processo de aprendizagem sobre a MQ, obtidos e analisados no contexto de uma proposta didática testada em 2019.2, na Universidade Estadual de Feira de Santana. A primeira etapa desse ciclo foi apresentada por Souza et al. (2018), em que se relata a elaboração da proposta didática; depois em Souza et al. (2020) que traz os resultados obtidos em estudo piloto envolvendo o contexto histórico pertinente a questão da (in)completude da MQ a partir do texto de Einstein et al. (1935). Com proposta de leitura de textos originais de cientistas, foram oportunizados momentos de discussão sobre o argumento de EPR e questões relativas ao determinismo clássico. Os estudantes, ao passo que conheciam o contexto histórico sobre a controvérsia da (in)completude, poderiam compreender os debates sobre o determinismo e realismo clássico, bem como a adoção do princípio de não-localidade.

Com a implementação da versão piloto, dos resultados iniciais, inferiu-se que o uso da HFC na tentativa de amenizar as dificuldades de compreensão conceitual, bem como a utilização de diferentes recursos didáticos (slides, vídeos, analogias), esbarra na falta de conhecimento introdutório da MQ. A estrutura da proposta didática mostrou-se carecer de uma articulação com conceitos básicos para melhor rendimento dos estudantes. Além disso, a mediação dialógica foi prejudicada, o que tornou as aulas bastante expositivas. Em consequência, a proposta passou por ajustes com um olhar mais atento para as estratégias de ensino, especialmente sobre o uso didático da HFC.

É reconhecido que o sucesso da proposta apresentada depende não somente do interesse dos estudantes em relação ao conteúdo específico, mas incluem a dependência da qualidade do processo de ensino-aprendizagem e das metodologias envolvidas. Com isso, os conteúdos a serem ensinados devem estar articulados com os propósitos finais de formação, buscando a contínua reflexão do estudante com a mediação do professor.

Dessa forma, mediados pela Engenharia Didática de Artigue (1994), segue-se, agora, apresentando uma reestruturação da proposta didática com o objetivo de vislumbrar melhores estratégias de articulação entre o ensino da MQ, o uso didático da HFC e os aspectos teóricoconceituais. Pois, se por um lado a HFC apresenta potencialidades para o processo de ensinoaprendizagem, por outro, o recurso adotado na versão piloto - leitura de textos originais - em nossa experiência limitou a interação, o questionamento, o diálogo e a criatividade em sala de aula.

Neste artigo, em sua primeira parte, apresenta-se as etapas de planejamento da nova versão da proposta didática, sendo as principais modificações percebidas quanto: (a) contexto 
histórico apresentado com inclusão de trechos dos textos originais, ao invés do texto na íntegra, dispostos em material de apoio elaborado ; (b) ênfase nos conceitos fundamentais da MQ para tratamento teórico-conceitual prévio; (c) foco na transposição didática para o ensino médio por meio de desafios propostos; (d) atividades de aprendizagem adequadas à Taxonomia de Bloom Revisada (TBR) - estrutura hierárquica dos objetivos educacionais, bem como seus níveis de conhecimento e cognição.

Na sequência, realizada a implementação, foram analisados os dados coletados. É intenção averiguar o nível de conhecimento percebido entre os estudantes e a aplicabilidade da proposta. $\mathrm{O}$ estudo encerra-se com uma reflexão sobre a ação, discutindo os resultados em relação aos níveis da TBR frente a contextualização por meio da HFC. Por fim, a HFC revelase como fator importante na formação de professores, ao criar um ambiente motivador para pensar práticas, técnicas, promover tomada de decisões influenciando positivamente na aprendizagem.

\section{Marco teórico e metodologia da pesquisa}

A proposta didática está fundamentada em alguns pressupostos do conceito de Zona de Desenvolvimento Proximal (ZDP) de Vigotski (2003) com maior reflexão quanto aos assuntos de ordem didático-pedagógicos para formação de professores. Para Vigotski, a ZDP é definida como a distância entre o nível de desenvolvimento real, que se costuma determinar através da solução independente de problemas, e o nível de desenvolvimento potencial, determinado através da solução de problemas sob a orientação de um adulto ou em colaboração com companheiros mais capazes. Dessa forma, dentre os pressupostos que embasaram a proposta, pode-se destacar a busca por oferecer possibilidades de envolvimento ativo dos estudantes, pois ao se eleger um contexto para o estudo dos conteúdos disciplinares, cria-se terrenos motivadores a serem desvelados.

Uma outra ideia fundamental para a implementação da proposta didática é a ideia de Transposição Didática de Chevallard (1991). Embora a complexidade da MQ seja inevitável, consideramos que através da HFC é possível conduzir os estudantes a um entendimento mais amplo da teoria privilegiando a discussão epistemológica dos conceitos científicos (MARTINS, 1990; MATTHEWS, 1994; MOURA; SILVA, 2018).

Há um conjunto de argumentos favoráveis ao uso didático da HFC. Advoga-se que a inclusão de elementos históricos e filosóficos no ensino facilita o entendimento do desenvolvimento histórico de determinado conteúdo, desperta o interesse pela ciência, humaniza a matéria, promove melhor compreensão dos conceitos científicos por traçar seu desenvolvimento e aperfeiçoamento, entre outros (MATTHEWS, 1995). A respeito da motivação para a ciência, tem-se a possibilidade de desmistificar a ideia de uma ciência sobrehumana aos olhos dos estudantes, superior às possibilidades dos mortais, transmitindo uma imagem adequada do que é a construção do conhecimento científico (GIL PÉREZ et al., 2001; MOURA; GUERRA, 2016). 
A HFC permite uma compreensão aprofundada dos conteúdos físicos, situando-os no contexto histórico, extraindo-os e projetando-os para contemplação dos diversos aspectos da produção científica, evitando ideias distorcidas da evolução científica como algo pronto e acabado (MARTINS, 2007). É apresentado o processo dinâmico da construção de novas ideias, explicações, modelos, teorias e leis, bem como as rupturas epistemológicas vivenciadas em um determinado momento do desenvolvimento científico. Através da HFC, é possível conduzir o estudante a compreender como o conhecimento é desenvolvido e estruturado; pois, "estratégias que sejam arquitetadas pela HFC objetivam mostrar aos estudantes uma ciência mais dinâmica e viva" (SILVA, 2012. p. 8). Portanto, contrapõe-se a uma visão excessivamente matematizada e descontextualizada das ciências (FORATO et al., 2012).

Desse modo, o uso didático da HFC desempenha função de apoiar o entendimento dos diversos contextos epistemológicos atuando como estrutura complementar em sala de aula; também poderá auxiliar na superação das dificuldades de leitura e/ou interpretação de textos por parte dos professores/estudantes, bem como suprir algumas limitações na formação acerca de discussões da natureza da ciência (HÖTTECKE et al., 2010; OLIVEIRA; SILVA, 2012; MOURA; GUERRA, 2016). Além de auxiliar na superação do ensino fragmentado intelectualmente que encontramos atualmente, abarcando uma educação com panorama mais amplo sobre a ciência (SILVA, 2012).

Do ponto de vista epistemológico, segundo Martins (2015), é possível explorar os próprios métodos e processos da ciência, cruciais para entender as diferenças entre o conhecimento científico e saberes alternativos. Pode-se explorar o caráter conjectural, a noção de verdade (não absoluta), a ideia de rupturas e continuidades, as mudanças ocorridas, as ideias de predição, consistência interna e simplicidade, assim como características da linguagem científica. $\mathrm{O}$ incentivo é para uma compreensão da natureza da ciência que inclua os métodos que produzem este conhecimento contemplando o desenvolvimento histórico da ciência e sua dinamicidade (KAMPOURAKIS, 2016).

Com essa percepção, é proposto uma contextualização histórica discutindo a dinâmica do processo de construção do conhecimento científico da MQ. Um ensino que promove uma contextualização histórica tendo como eixo condutor a HFC refere-se a uma "tendência que explora as componentes históricas, filosóficas, sociais e culturais da ciência por meio de enfoques e abordagens variadas, na tentativa de promover uma formação que supere a demarcação entre o ensino dos conteúdos científicos e o de seus contextos de produção" (PRESTES; CALDEIRA, 2009, p. 2).

Uma vez que a HFC é adotada como eixo condutor no ensino de MQ possibilita uma abordagem contextual que contribui com a formação de professores ao promover o desenvolvimento de pelo menos três competências, que segundo Matthews (1994) são: 1) o conhecimento e a apreciação da ciência que ensinam; 2) alguma compreensão da HFC; e 3) alguma teoria ou visão educacional que informe suas atividades na sala de aula. Segundo 
Rosales et al. (2014), essa abordagem auxilia na compreensão das mudanças aceleradas que a ciência proporciona e que influência nossos estilos de vida e nossos próprios projetos de bem estar.

Assim, o conteúdo de MQ será apresentado pela história com destaque para seu impacto científico, tecnológico e filosófico na cultura dos séculos XX e XXI. A contextualização histórica no ensino de MQ é uma estratégia capaz de estimular a análise dos contextos pelos quais cada conceito foi proposto, elucidando as relações e os aspectos centrais do pensamento científico em seus respectivos tempos. Sob esta perspectiva, a contextualização histórica é compreendida como a inserção de conhecimentos disciplinares em uma realidade que atua como um ponto de apoio para a construção do conhecimento. É considerada as ações produzidas pelos diferentes atores da ciência, que deve levar ao entendimento de como os cientistas disseminam suas ideias, como estabelecem relações sociais e que papel a leitura, a escrita e o discurso desempenham na produção científica (MODY, 2015).

No campo didático, através do conceito de ZDP, o ensino de MQ é planejado partindo dos limites dos efeitos clássicos e quânticos com destaque para o desenvolvimento da MQ moderna por meio do questionamento levantado por Einstein, Podolsky e Rosen a respeito da completude da MQ. A questão da não-localidade e o abandono do determinismo serão discutidos de modo a aproximar dos estudantes aspectos epistemológicos que contribua com a promoção de uma compreensão mais sofisticada da teoria quântica. Os documentos históricos que envolvem esses conteúdos implicam em um contexto de aceitação de um novo paradigma na Física.

No processo de interação social, abriu-se o diálogo sobre como que o curto artigo de Einstein, Podolsky, Rosen (1935) desencadeou tamanhas revoluções. Compartilhamos a discussão do experimento mental envolvendo estados emaranhados, também discutidos naquele mesmo ano por Bohr e Schrödinger, onde a expressão 'emaranhamento' foi utilizada pela primeira vez. Como os autores como David Bohm e John Bell, por exemplo, tentam mostrar se a MQ é (ou não) uma descrição completa da realidade, e os argumentos apresentados foram fonte de muita incompreensão e controvérsias. Que, somente passados quase 30 anos, a controvérsia sobre a completude da MQ, se traduziu em termos físicos matemáticos e, posteriormente, em práticas de laboratório. Assunto, inicialmente, restrito a aspectos epistemológicos é então revistado por Bell, em 1964, que apresenta suas famosas desigualdades e, depois deslocado ao crivo dos testes em laboratório com as experiências de Aspect, Dalibard, Roger (1982), levando a conclusão de que o realismo clássico não mais poderia ser sustentado.

Nesta perspectiva, para criar situações de aprendizagem envolvendo a $M Q$, entre várias possibilidades de discussão, propomos uma abordagem através de seus contextos de desenvolvimento evidenciando as dificuldades percorridas pelos cientistas na sua época, além de operá-los com uso mínimo do formalismo matemático buscando estimular o estudante a 
colocar em movimento o que já aprendeu ou domina, em situações em que precisa de alguém mais experiente que the oriente e auxilie a internalizar conceitos quânticos. Logo, será possível verificar as funções que ainda não amadureceram, mas que estão em processo de amadurecimento.

Em relação ao formalismo matemático, adotou-se o formalismo de Dirac considerado facilitador e adequado ao entendimento da MQ (PESSOA JR., 2006). O formalismo de Dirac simplifica a matemática envolvida nos fenômenos quânticos, e, portanto, a parte conceitual poderá ser melhor discutida e entendida pelos estudantes. Outra razão que justifica o contato com esse formalismo no curso de licenciatura é sua aproximação com a álgebra linear. $\mathrm{O}$ conhecimento que os estudantes já possuem sobre vetores irá facilitar o processo de compreensão da notação.

Quanto à metodologia de pesquisa adotada, optou-se pelo método qualitativo da Engenharia Didática de Artigue (1994). Salienta-se que a Engenharia Didática propõe quatro fases: 1) análises prévias; 2) concepção e análise a priori; 3) experimentação; 4) análise a posteriori e validação. Aqui, é retomada a fase quatro partindo dos resultados da versão piloto. Aplicou-se a proposta didática em componente curricular que permite concatenar o conteúdo específico com o pedagógico da Universidade Estadual de Feira de Santana com um público de 7 estudantes do $7^{\circ}$ período do curso. Foram utilizados três tipos de coleta de dados: observação, gravação de áudio e vídeo e documento (atividades individuais). Em todos os procedimentos metodológicos, considerou-se essencial o papel da interação social, uma vez que foram planejadas em função das falas (gravadas em vídeo) dos estudantes, enquanto que nas atividades individuais, o objetivo foi analisar o que cada estudante era capaz de fazer de forma autônoma (desenvolvimento real) e o que estava em processo de formação (desenvolvimento potencial).

Nesse trabalho, são sinalizadas as modificações necessárias para melhor contribuir com a aprendizagem dos estudantes no estudo de MQ, buscando ajustar os aspectos limitantes para o desenvolvimento de competências e habilidades esperadas em seu processo formativo. Agora, as atividades didáticas foram planejadas de modo a atuarem juntamente com os textos de apoio elaborados como estruturas mediadoras no processo de construção conceitual entre os sujeitos pesquisados.

Para isso, usamos a técnica da TBR que segundo Anderson e Krathwohl (2001) oferece meios de detectar se a instrução, bem como as atividades realizadas, teve efeito sobre a dimensão cognitiva ao final de um curso, além de possibilitar avaliar os ganhos na aprendizagem. Assim, na elaboração das atividades tentou-se buscar o equilíbrio entre o referencial teórico e a TBR. Os aspectos de desenvolvimento cognitivo, competência e habilidade foram relacionados de forma a atribuírem característica bidimensional sendo combinados ao tipo de conhecimento a ser adquirido (Dimensão do conhecimento) e o processo utilizado para a aquisição desse conhecimento (Dimensão do processo cognitivo). Salienta-se que com a intenção de criar espaços profícuos para a integração dos objetivos de 
ensino ao curso, estabeleceram-se objetivos de aprendizagem articulando aos conteúdos Conceituais, Procedimentais e Atitudinais (CPA) (COLL et al., 1992).

\section{Proposta didática}

\section{III.1 Linhas de reestruturação (versão piloto - versão atual)}

A proposta didática mantém uma estrutura alternativa, uma vez que introduz o conteúdo com situação contexto problematizadora - visando a motivação -, depois segue com um tratamento teórico e revisão sobre aspectos básicos da Teoria Quântica. Os principais acréscimos são em relação a conteúdos que irão dar suporte para compreensão da discussão em torno do argumento de EPR. É inserido na proposta os fundamentos da Teoria Quântica: postulados, processo de medição de sistemas quânticos e o formalismo de Dirac (linguagem matemática adotada) - Ver Quadro 1.

$\mathrm{Na}$ sequência, uma abordagem histórica através do argumento de EPR até as experiências que concordam com as previsões estatísticas da MQ é desenvolvida com introdução de formalismo e interpretação, desmembrado nas aplicações práticas. O trabalho com uso da HFC foi viabilizado através da inserção de elementos da história por meio de trechos dos textos originais e de fontes secundárias que foram incluídos no material de apoio, a fim de aproximá-los da linguagem e dos argumentos dos cientistas. Além disso, buscou-se discutir, de modo pormenorizado, como ensinar tópicos de MQ no ensino médio salientando desafios à futura prática docente que culmina em uma oficina pedagógica com destaque para assuntos de ordem didático-pedagógicos.

Quadro 1 - Ajustes da proposta didática (problemas enfrentados e modificações).

\begin{tabular}{|c|c|c|c|}
\hline $\begin{array}{c}\text { VERSÃO PILOTO } \\
\text { (como era) }\end{array}$ & Resultados & $\begin{array}{c}\text { Justificativa para } \\
\text { adequações }\end{array}$ & $\begin{array}{c}\text { VERSÃO ATUAL } \\
\text { (o que muda) }\end{array}$ \\
\hline $\begin{array}{l}\text { Objetivos gerais de } \\
\text { aprendizagem } \\
\text { 1) Compreender a } \\
\text { dinamicidade do processo } \\
\text { de construção do } \\
\text { conhecimento científico } \\
\text { 2) Entender a origem e } \\
\text { solução do argumento de } \\
\text { EPR dialogando com as } \\
\text { discussões teóricas e } \\
\text { experimentais da não- } \\
\text { localidade }\end{array}$ & $\begin{array}{l}\text { O entendimento do episódio } \\
\text { histórico esbarrou na falta de } \\
\text { conhecimento conceitual } \\
\text { prévio }\end{array}$ & $\begin{array}{l}\text { A compreensão histórico- } \\
\text { epistemológica não pode ser } \\
\text { alcançada desarticulada da } \\
\text { discussão conceitual. } \\
\text { Portanto, buscou-se } \\
\text { oportunizar um momento } \\
\text { para relembrar/introduzir os } \\
\text { conceitos fundamentais da } \\
\text { teoria a partir dos } \\
\text { postulados da MQ e do } \\
\text { problema da medição com } \\
\text { uso do formalismo de } \\
\text { Dirac. }\end{array}$ & $\begin{array}{l}\text { Acrescentado: } \\
\text { 3) Entender os conceitos } \\
\text { fundamentais da MQ }\end{array}$ \\
\hline $\begin{array}{ll}\text { Conteúdo Programático } \\
\\
\text { 1. } \\
\text { 2. Argumento de EPR } \\
\text { 3. } & \text { Problema da medição } \\
\text { 4. } & \text { Aplicações da MQ } \\
\text { 5. } & \text { Planejamento e prática }\end{array}$ & $\begin{array}{l}\text { O conteúdo da MQ moderna } \\
\text { dificilmente é discutido em } \\
\text { disciplinas introdutórias. Ao } \\
\text { passo que é relevante na } \\
\text { formação inicial é também } \\
\text { desafiador. É preciso pensar } \\
\text { como nivelar as discussões }\end{array}$ & 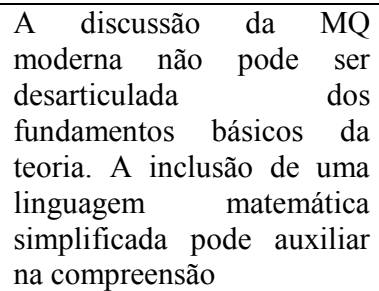 & $\begin{array}{l}\text { Acrescentados: } \\
\text { 6. Diferenças entre a } \\
\text { Física Clássica e a MQ } \\
\text { 7. Formalismo de Dirac } \\
\text { 8. Postulados da MQ } \\
\text { 9. Interpretações }\end{array}$ \\
\hline
\end{tabular}




\begin{tabular}{|c|c|c|c|}
\hline $\begin{array}{l}\text { Recursos didáticos } \\
\text { Slides, vídeos, } \\
\text { analogias, textos originais } \\
\text { dos cientistas }\end{array}$ & $\begin{array}{l}\text { A leitura do texto original } \\
\text { sem um conhecimento } \\
\text { conceitual prévio é obstáculo } \\
\text { a aprendizagem }\end{array}$ & $\begin{array}{l}\text { Para subsidiar o estudo } \\
\text { proposto, ao invés da leitura } \\
\text { na integra dos textos } \\
\text { originais, um material de } \\
\text { apoio é elaborado com as } \\
\text { devidas adequações }\end{array}$ & $\begin{array}{l}\text { Acrescentado: } \\
\text { Material de apoio }\end{array}$ \\
\hline $\begin{array}{l}\text { Taxonomia de Bloom } \\
\underline{\text { Revisada }} \\
\begin{array}{l}\text { Adotada para avaliação de } \\
\text { resultados }\end{array}\end{array}$ & $\begin{array}{l}\text { Quando pensamos em ZDP, } \\
\text { devemos considerar o que o } \\
\text { estudante sabe e o que o } \\
\text { professor pode ajudá-lo a } \\
\text { aprender }\end{array}$ & $\begin{array}{l}\text { É preciso ter um olhar mais } \\
\text { atento aos processos } \\
\text { cognitivos e ter uma } \\
\text { estrutura que melhor avalie } \\
\text { os estudantes }\end{array}$ & $\begin{array}{l}\text { Usar a TBR como suporte } \\
\text { metodológico no } \\
\text { planejamento e elaboração } \\
\text { das atividades, bem como } \\
\text { para a avaliação dos } \\
\text { rendimentos }\end{array}$ \\
\hline $\begin{array}{l}\text { Transposição didática } \\
\text { Ao final da proposta com } \\
\text { entrega de plano de aula e } \\
\text { apresentação de miniaula }\end{array}$ & ticos & $\begin{array}{l}\text { Preparar progressivamente } \\
\text { os estudantes para refletir o } \\
\text { processo de transposição } \\
\text { didática }\end{array}$ & $\begin{array}{l}\text { Inclusão de "desafios" na } \\
\text { proposta com socialização } \\
\text { de um plano de aula na } \\
\text { modalidade de oficina }\end{array}$ \\
\hline
\end{tabular}

Nessa estrutura, a proposta didática foi replanejada para acontecer 10 encontros (20 aulas com duração de 50 minutos cada), além de $2 \mathrm{~h}$ /aula extras para a execução de uma oficina pedagógica. No Quadro 2, apresenta-se o plano esquemático. Para melhor compreensão, salientamos que: 1) As dimensões CPA são então representadas por: C1 representa o conteúdo conceitual 1; P1 representa o conteúdo procedimental 1; A1 representa o conteúdo atitudinal 1 e assim por diante; 2) As atividades de aprendizagem são indicadas por AT1, AT2, ..., bem como os desafios D1, D2, ... D6.

Quadro 2 - Plano esquemático da proposta didática - versão aprimorada.

\begin{tabular}{|c|c|c|c|}
\hline $\begin{array}{l}\text { Aulas } \\
\text { (50min } \\
\text { cada) }\end{array}$ & Objetivos de ensino & $\begin{array}{c}\text { Objetivos de } \\
\text { aprendizagem (CPA) }\end{array}$ & Atividades e materiais propostos \\
\hline 1 e 2 & $\begin{array}{l}\text { Apresentar a proposta } \\
\text { didática dando ciência } \\
\text { dos objetivos e de todas } \\
\text { as atividades que serão } \\
\text { realizadas. } \\
\text { Realizar o levantamento } \\
\text { das concepções prévias } \\
\text { sobre os conceitos } \\
\text { fundamentais da } \\
\text { Mecânica Quântica } \\
\text { (MQ). } \\
\text { Contextualizar o ensino } \\
\text { de MQ através da } \\
\text { Criptografia Quântica. } \\
\text { Introduzir aspectos da } \\
\text { Transposição Didática } \\
\text { (TD) voltada ao ensino } \\
\text { médio. }\end{array}$ & $\begin{array}{l}\text { (C1) Reconhecer as } \\
\text { diferenças entre a MQ e a } \\
\text { Mecânica Clássica. } \\
\text { (A1) Dialogar sobre a o } \\
\text { impacto científico e } \\
\text { tecnológico que promoveu a } \\
\text { "nova MQ". }\end{array}$ & $\begin{array}{l}\text { Apresentação do trabalho que será realizado. } \\
\text { Entrega e explicação da estrutura do material } \\
\text { didático e os de leitura complementar. } \\
\text { Utilização de uma atividade para coletar as } \\
\text { concepções prévias dos estudantes (AT0). } \\
\text { A discussão será iniciada por uma situação- } \\
\text { problema sobre uso da Criptografia Quântica na } \\
\text { sociedade atual. Em seguida, faz-se apontamentos } \\
\text { sobre o contexto histórico da "nova MQ", algumas } \\
\text { diferenças entre a Física Clássica e a MQ e acerca } \\
\text { da dinamicidade no fazer científico. } \\
\text { No final dessas aulas será solicitado que os } \\
\text { estudantes façam em casa a AT1 e o D1. Essas } \\
\text { atividades serão discutidas na próxima aula. }\end{array}$ \\
\hline 3 e 4 & $\begin{array}{l}\text { Introduzir o formalismo } \\
\text { de Dirac. } \\
\text { Discutir aspectos da TD } \\
\text { voltada ao ensino médio. }\end{array}$ & $\begin{array}{l}\text { (C2) Compreender como o } \\
\text { conhecimento de vetores } \\
\text { introduz a notação de Dirac } \\
\text { e como esta descreve os } \\
\text { fenômenos quânticos. } \\
\text { (C3) Conhecer como a MQ } \\
\text { descreve a informação na }\end{array}$ & $\begin{array}{l}\text { Apresentação do formalismo de Dirac associado ao } \\
\text { estudo dos vetores e espaço vetoriais. } \\
\text { Os processos de Criptografia Quântica serão } \\
\text { reforçados através da analogia de Alice e Bob. } \\
\text { No final dessas aulas será solicitado que os }\end{array}$ \\
\hline
\end{tabular}




\begin{tabular}{|c|c|c|c|}
\hline & & $\begin{array}{l}\text { Criptografia Quântica. } \\
\text { (P1) Pesquisar } \\
\text { possibilidades para ensinar } \\
\text { MQ no nível médio. }\end{array}$ & estudantes façam em casa a AT2 e o D2. \\
\hline 5 e 6 & $\begin{array}{l}\text { Apresentar através dos } \\
\text { postulados conceitos } \\
\text { fundamentais da MQ. } \\
\text { Retomar discussão sobre } \\
\text { a TD. }\end{array}$ & $\begin{array}{l}\text { (C4) Conhecer } \quad \text { os } \\
\text { postulados da MQ. } \\
(\text { A2) Discutir sobre } \\
\text { natureza quântica da } \\
\text { criptografia. } \\
\text { (A3) Tomar consciência } \\
\text { sobre os processos de TD. }\end{array}$ & $\begin{array}{l}\text { A aula será iniciada com a leitura de uma história } \\
\text { extraída e traduzida do livro Quantum Mechanics } \\
\text { and experience de David Albert (1992) para } \\
\text { introduzir os postulados da MQ. } \\
\text { Em seguida, será discutido a descrição de um } \\
\text { sistema físico e o processo de medição. } \\
\text { O professor irá provocar os estudantes para que eles } \\
\text { discutam a analogia Alice e Bob da criptografia } \\
\text { incluindo o tratamento quântico da informação. } \\
\text { No final dessas aulas será solicitado que os } \\
\text { estudantes façam em casa a AT3 e o D3. }\end{array}$ \\
\hline 7 e 8 & $\begin{array}{l}\text { Discutir o processo da } \\
\text { medição na experiência } \\
\text { de Stern-Gerlach. } \\
\text { Retomar discussão sobre } \\
\text { a TD. }\end{array}$ & $\begin{array}{l}\text { (C5) Compreender o } \\
\text { comportamento das } \\
\text { partículas subatômicas e de } \\
\text { como estas colocam em } \\
\text { questionamento a realidade } \\
\text { (P2) Utilizar a notação de } \\
\text { Dirac na MQ. } \\
\text { (A4) Dialogar sobre a } \\
\text { natureza quântica. } \\
\text { Repete-se o (A3), ver. }\end{array}$ & $\begin{array}{l}\text { Retomada do processo de medida discutindo a } \\
\text { aplicação das diferenças no comportamento } \\
\text { quântico a partir da experiência de Stern-Gerlach } \\
\text { (SG). } \\
\text { O professor irá promover uma discussão sobre a } \\
\text { interpretação dos resultados experimentais com } \\
\text { ênfase na interpretação de Copenhagen, bem como } \\
\text { irá introduzir o argumento de EPR e o gato de } \\
\text { Schrödinger. } \\
\text { No final dessas aulas será solicitado que os } \\
\text { estudantes façam em casa a AT4 e o D4. }\end{array}$ \\
\hline 9 e 10 & $\begin{array}{l}\text { Sintetizar os conceitos } \\
\text { fundamentais da MQ. }\end{array}$ & 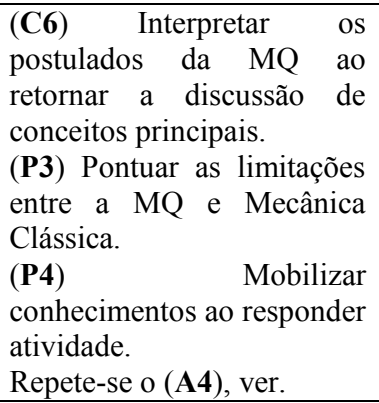 & $\begin{array}{l}\text { Retomar os Postulados da MQ e a analogia sobre o } \\
\text { processo de medição associando a Criptografia } \\
\text { Quântica o formalismo de Dirac. } \\
\text { Solicitar que os estudantes respondam a AT5. } \\
\text { Respondida a atividade haverá uma socialização } \\
\text { das respostas e um diálogo sobre as mesmas. }\end{array}$ \\
\hline 11 e 12 & $\begin{array}{l}\text { Realizar uma discussão } \\
\text { crítica e reflexiva sobre } \\
\text { o argumento de EPR e } \\
\text { as consequências } \\
\text { epistemológicas para a } \\
\text { MQ. }\end{array}$ & $\begin{array}{l}\text { (C7) Compreender o } \\
\text { argumento de EPR e suas } \\
\text { consequências para a MQ; } \\
\text { (A5) Dialogar sobre a } \\
\text { natureza quântica e de como } \\
\text { exigem uma mudança } \\
\text { paradigmática; } \\
\text { Repete-se o (A3), ver; }\end{array}$ & $\begin{array}{l}\text { São apresentados aos estudantes os trabalhos de } \\
\text { Einstein et al. (1935) e de Schrödinger (1935) e se } \\
\text { propõe socialização de opiniões pelos estudantes } \\
\text { frente a leitura realizada do material de apoio. } \\
\text { Em seguida, o professor irá analisar, juntamente } \\
\text { com os estudantes, os interesses que estão por trás } \\
\text { de cada argumento apresentado. Será enfatizado a } \\
\text { importância de saber discernir quais fontes de } \\
\text { informação são confiáveis ao passo que é discutido } \\
\text { trechos de texto de cientistas. } \\
\text { Uma discussão sobre o paradoxo EPR e Gato de } \\
\text { Schrödinger sobre a incompletude da MQ será } \\
\text { estabelecida. Um vídeo sobre o "Gato de } \\
\text { Schrödinger" será exibido. } \\
\text { Reforçar a importância da compreensão do } \\
\text { comportamento das partículas subatômicas e de } \\
\text { como estas colocaram em questionamento a } \\
\text { realidade física. } \\
\text { No final dessas aulas será solicitado que os }\end{array}$ \\
\hline
\end{tabular}




\begin{tabular}{|c|c|c|c|}
\hline & & & estudantes façam em casa a AT6 e o D5. \\
\hline 13 e 14 & $\begin{array}{l}\text { Discutir os principais } \\
\text { aspectos da teoria de } \\
\text { variáveis ocultas. } \\
\text { Discutir a detecção do } \\
\text { emaranhamento, a sua } \\
\text { dinâmica e relação com } \\
\text { outro conceito central na } \\
\text { MQ, o de não- } \\
\text { localidade. }\end{array}$ & $\begin{array}{l}\text { (C8) Introduzir a discussão } \\
\text { sobre teoria de variáveis } \\
\text { ocultas através das } \\
\text { desigualdades de Bell. } \\
\text { (P5) Apresentar as } \\
\text { anotações e dúvidas para } \\
\text { socializar as informações } \\
\text { com a turma. } \\
\text { (A6) Dialogar sobre como } \\
\text { as desigualdades de Bell } \\
\text { influenciou na produção do } \\
\text { conhecimento da MQ. }\end{array}$ & $\begin{array}{l}\text { Apresentação das anotações e/ou dúvidas dos } \\
\text { estudantes e a mediação do professor nas discussões } \\
\text { sobre a temática. } \\
\text { Discutir o teorema de Bell e usar uma analogia para } \\
\text { discutir a teoria de variáveis ocultas. Ainda, discutir } \\
\text { sobre o processo quântico do teletransporte com } \\
\text { analogia a Alice e Bob. } \\
\text { Solicitação aos estudantes a leitura de textos } \\
\text { sugeridos e que, se desejarem, façam anotações } \\
\text { para discutir na próxima aula. }\end{array}$ \\
\hline 15 e 16 & $\begin{array}{l}\text { Discutir como, pela } \\
\text { ideia de emaranhamento } \\
\text { quântico, o ato de medir } \\
\text { um sistema quântico } \\
\text { altera os resultados } \\
\text { esperados. } \\
\text { Aprofundar } \\
\text { compreensão sobre as } \\
\text { desigualdades de Bell, } \\
\text { bem como sua violação } \\
\text { através dos } \\
\text { experimentos de Aspect. }\end{array}$ & $\begin{array}{l}\text { (C9) Entender como o } \\
\text { experimento de Aspect } \\
\text { elucidou o argumento de } \\
\text { EPR. } \\
\text { (A7) Discutir sobre a } \\
\text { interpretação de fenômenos } \\
\text { quânticos. } \\
\text { (A8) Ponderar sobre a } \\
\text { dinamicidade na produção } \\
\text { do conhecimento científico. } \\
\text { Repete-se o (A1), ver. }\end{array}$ & $\begin{array}{l}\text { O professor enfatizará os aspectos dos fenômenos } \\
\text { quânticos estudados até o momento derivados do } \\
\text { argumento de EPR explorando as relações } \\
\text { históricas e conceituais com as desigualdades de } \\
\text { Bell. Será destacada as contradições dos fenômenos } \\
\text { quânticos frente as questões próprias à natureza da } \\
\text { ciência. } \\
\text { Provocação e mediação sobre a importância do } \\
\text { resultado obtido por Aspect nos seus experimentos } \\
\text { e de como invalida a explicação do comportamento } \\
\text { correlacional de um sistema emaranhado por } \\
\text { variáveis ocultas. } \\
\text { Será enfatizado a importância de se conhecer os } \\
\text { processos históricos de construção do } \\
\text { conhecimento para a formação docente. } \\
\text { No final dessas aulas será solicitado que os } \\
\text { estudantes façam em casa a AT7. }\end{array}$ \\
\hline 17 e 18 & $\begin{array}{l}\text { Introduzir as principais } \\
\text { interpretações da MQ. }\end{array}$ & $\begin{array}{l}\text { (C10) Conhecer as } \\
\text { principais interpretações. } \\
\text { (P6) Desenvolver } \\
\text { pensamento crítico sobre a } \\
\text { natureza quântica. }\end{array}$ & $\begin{array}{l}\text { Serão discutidas as principais interpretações da } \\
\text { MQ. Na sequência, os estudantes serão convidados } \\
\text { a responder em sala a AT8, um questionário } \\
\text { objetivo, através da qual retomaremos as discussões } \\
\text { com socialização das respostas e um diálogo sobre } \\
\text { as mesmas. }\end{array}$ \\
\hline 19 e 20 & $\begin{array}{l}\text { Perceber o impacto } \\
\text { científico, tecnológico e } \\
\text { filosófico que a MQ } \\
\text { trouxe para a cultura do } \\
\text { século XX e XXI. } \\
\text { Realizar uma discussão } \\
\text { crítica e reflexiva sobre } \\
\text { a TD }\end{array}$ & $\begin{array}{l}\text { (A9) Dialogar sobre a } \\
\text { prática docente em termos } \\
\text { de ensino da MQ no nível } \\
\text { médio. } \\
\text { (P7) Produzir um plano de } \\
\text { aula. } \\
\text { Repete-se o (A1), ver. }\end{array}$ & $\begin{array}{l}\text { Essa aula será iniciada com a discussão das } \\
\text { implicações da MQ - computação quântica; } \\
\text { criptografia quântica; teletransporte quântico e } \\
\text { discutiremos como a MQ se faz presente em vários } \\
\text { campos do saber e como tem influenciado a } \\
\text { sociedade. } \\
\text { No final dessas aulas será solicitado que os } \\
\text { estudantes elaborem em casa um plano de aula para } \\
\text { ser apresentado na oficina, trata-se do D6. }\end{array}$ \\
\hline Oficina & $\begin{array}{l}\text { Discutir os desafios ao } \\
\text { ensino de MQ à nível } \\
\text { médio em termos de TD. } \\
\text { Socializar os planos de } \\
\text { aula e estimular } \\
\text { reflexões sobre o ensino } \\
\text { de tópicos da MQ no } \\
\text { nível médio. } \\
\text { Esclarecer possíveis } \\
\text { dúvidas remanescentes. }\end{array}$ & $\begin{array}{l}\text { (P8) Apresentar o plano de } \\
\text { aula para o ensino médio. } \\
\text { (P9) Demonstrar } \\
\text { competências e habilidades } \\
\text { pedagógicas. } \\
\text { (A10) Posicionar-se acerca } \\
\text { do ensino de MQ no nível } \\
\text { médio. } \\
\text { Repete-se o (A9), ver. }\end{array}$ & $\begin{array}{l}\text { Esta oficina tem o propósito de criar um espaço } \\
\text { para discutir caminhos para a TD voltada ao ensino } \\
\text { médio. Durante a proposta didática os estudantes } \\
\text { foram desafiados progressivamente a construir um } \\
\text { plano de aula, e, portanto, este momento se } \\
\text { constitui de um espaço de socialização de produção. } \\
\text { O professor enfatizará que aspectos precisam ser } \\
\text { considerados ao se pensar no ensino da MQ em } \\
\text { relação ao público-alvo. Será dado destaque ao fato } \\
\text { de se a proposta é adequada em termos de conteúdo } \\
\text { e significado para o aluno da escola básica. } \\
\text { No final da oficina será solicitado, estabeleceremos } \\
\text { um feedback avaliativo sobre o trabalho } \\
\text { desenvolvido. }\end{array}$ \\
\hline
\end{tabular}




\section{III.2 Descrição das aulas}

As aulas foram estruturadas de modo a criar uma zona de desenvolvimento com relação às diferenças entre a MQ e a Física Clássica, enfatizando a MQ moderna para ampla discussão do realismo e localidade ao envolver a interação de dois sistemas descritos por um estado quântico emaranhado. Todos os encontros dispõem de ferramentas de apoio ao ensino, como sugestões de simulações computacionais, uso de analogias, atividades, slides e vídeos, além de indicações de leituras complementares e materiais de consulta, incluindo também aspectos concernentes à transposição didática.

O plano da proposta foi dividido em dois momentos (Quadro 2). No primeiro momento (aulas de 1 a 10), é discutido aspectos clássicos e quânticos da Física demarcando a transição em direção ao estabelecimento da Teoria Quântica. Em seguida, são apresentados conceitos fundamentais para caracterizar o sistema quântico e introduzir a linguagem matemática. Os estudantes são direcionados a compreender o comportamento das partículas subatômicas e as limitações entre Física Clássica e MQ.

Aulas 1 e 2 - A proposta didática é apresentada aos estudantes para que eles tenham ciência dos objetivos e de todas as atividades que serão realizadas. Em seguida, a atividade (AT0) é aplicada para levantamento das concepções prévias dos estudantes. Após ser respondida, cada estudante, de forma voluntária, expõe sua resposta. De acordo com Vigotski (2003), aquilo que os estudantes trazem consigo ao ser organizado pelo professor, com novas informações, leva-os à construção do conhecimento. Através da mediação em um percurso constituído de interações, pode-se alcançar a evolução conceitual que se justifica pela internalização de novas informações.

Na sequência, um breve esquema da evolução da Teoria Quântica é apresentado. De modo geral, são pontuados conceitos associados à velha Teoria Quântica seguidos de uma reflexão sobre o seu desenvolvimento. É representado historicamente uma mistura de aspectos clássicos e quânticos da Física, passando pela transição em direção ao estabelecimento da teoria. Também é discutindo o uso da criptografia quântica. Ao término da aula é solicitado a realização da atividade de aprendizagem (AT1) a fim de revisar o conteúdo de dualidade onda-partícula direcionando-os a um primeiro contato com as interpretações. Ainda nessas aulas, um primeiro passo para pensar na transposição didática é dado ao solicitar a leitura do artigo de Brockington e Pietrocola (2005) sobre conceitos de Física moderna no ensino médio (D1).

Aulas 3 e 4 - Nessas aulas, com um caráter expositivo, uma introdução ao formalismo de Dirac é realizada a partir das principais relações com a Teoria Quântica. Utiliza-se da conceituação de vetores para facilitar na percepção da linguagem reforçando a importância de conhecer o formalismo de modo a representar quantitativamente fenômenos quânticos. Em seguida, é solicitado que os estudantes respondam a atividade AT2, para verificar sua compreensão. Além disso, procura orientar as discussões sobre transposição 
didática (D2), incentivando os estudantes a buscarem na literatura, pelo menos, cinco artigos que discorram sobre o ensino tópicos de MQ no nível médio.

Aulas 5 e 6 - De início, o professor expõe uma história extraída e traduzida do livro Quantum Mechanics and experience de David Albert (1992) para descrever um sistema físico e o processo de medição. Procura-se enfatizar os postulados quânticos de modo a levar os estudantes a compreensão que é o meio de caracterizar um sistema e calcular suas propriedades. A aula é encerrada com a solicitação da realização da atividade AT3, através da qual o estudante poderá aprofundar seu entendimento sobre as diferenças entre as visões clássica e quântica dos fenômenos da natureza.

Aulas 7 e 8 - Um comparativo dos processos clássicos e quânticos, partindo da descrição do estado físico até a evolução temporal do estado é realizado. Em seguida, para ampliar a discussão sobre a medida quântica, passa-se a perceber o processo da medição na experiência de Stern-Gerlach, dando margem a superposição de estados e a interpretação de Copenhagen. Outras interpretações são vistas a partir da AT4 que incentiva os estudantes a rever a experiência de Stern-Gerlach sobre outras perspectivas.

Aulas 9 e 10 - Uma síntese das discussões já estabelecidas é realizada. A atividade (AT5), baseada nos trabalhos de Ostermann, Ricci (2004), Montenegro, Pessoa Jr. (2002) e Didis (2010), que envolve os conceitos estudados deve ser realizada. Após responderem as questões, retoma-se cada uma delas e, coletivamente, inicia-se uma sistematização das respostas. Com isso, tenta-se fomentar a discussão em sala, deixando-os fundamentar seus argumentos. É formalizado com breve explanação os principais conceitos da MQ como dualidade onda-partícula, princípio da incerteza, propriedades dos objetos quânticos, postulados e propriedades do formalismo de Dirac.

No segundo momento (aulas de 11 a 20), são apresentados elementos históricos para refletir sobre as consequências epistemológicas dos avanços teóricos e experimentais da MQ. É dada ênfase na ruptura com o determinismo e a aceitação da não-localidade no mundo quântico, explicitando algumas interpretações que permeiam o assunto.

Aulas 11 e 12 - É explicada a ideia de "Gedankenexperiment" para apresentação do argumento de EPR e suas consequências epistemológicas, bem como o paradoxo do Gato de Schrödinger para mostrar a impossibilidade de considerar efeitos quânticos com olhar macroscópico, ou seja, com uma visão da Física clássica. São formalizados os conceitos de determinismo, realidade, não-localidade e pontuam-se aspectos sobre a detecção do emaranhamento quântico. É enfatizado o contexto histórico dos desenvolvimentos da Teoria Quântica, a fim compreender o processo de construção do conhecimento científico e sua associação a outros acontecimentos históricos importantes. Para maiores esclarecimentos sobre os experimentos de pensamentos, sugere-se a atividade AT6, respaldada em Greca (2000) e Netto (2015).

Aulas 13 e 14 - Critérios matemáticos da MQ são vistos. Novamente, utilizaram-se de trechos de textos de cientistas, desta vez do texto de Bell (1964), para discussão da não- 
localidade e suas desigualdades. Nessas aulas, será possível ampliar um pouco mais sobre o contexto histórico e os personagens que trabalharam nos estudos relativos à ruptura com o determinismo. Na parte de transposição didática, os estudantes são levados a refletir sobre o processo de ensinar e aprender a MQ (D5). É sugerido a leitura das referências de Rigolin, Rieznik (2005) e Piqueira, (2011) sobre aplicações da teoria.

Aulas 15 e 16 - É realizada uma discussão sobre o argumento de EPR com olhar nos experimentos de Aspect et al. (1982). A contextualização histórica acerca do debate interpretativo em torno do abandono do determinismo e a 'aceitação' da não-localidade é então concluída. Feito isso, através da AT7, sondaram-se as concepções de ciências que os estudantes possuem. As questões dessa atividade foram adaptadas de Martins (2015).

Aulas 17 e 18 - Uma discussão final sobre as interpretações da MQ, buscando desenvolver uma visão mais ampla da natureza quântica é realizada. É solicitado que os estudantes respondam na aula a AT8 - essa atividade é composta de três questões retiradas de Montenegro e Pessoa Jr. (2002).

Aulas 19 e 20 - Nas últimas aulas, uma discussão sobre as aplicações da MQ é oportunizada. Essas aulas foram respaldadas pelo texto de Nunes (2007) intitulado 'Física Quântica para Todos'. Os estudantes são levados a reconhecer a tecnologia como construção humana, compreendendo seu o papel para o desenvolvimento e inovação.

Oficina - A partir de um plano de aula previamente elaborado, será discutido os desafios para o ensino de tópicos da MQ no nível médio por meio da transposição didática. Discute-se a relevância dos estudantes do ensino médio, enquanto cidadãos contemporâneos, desenvolver uma compreensão qualitativa mínima da teoria. Acredita-se que aos futuros professores deve ser garantido um processo formativo para além do conteúdo específico e, portanto, as questões dos desafios propostos têm o objetivo de permitir ampliar seus conhecimentos para situações práticas. Por fim, um momento de Feedback é proposto com algumas considerações pertinentes.

\section{III.3 Descrição do material de apoio e das atividades de aprendizagem}

O material de apoio elaborado inclui as atividades (indicadas por AT0 a AT9) e os desafios propostos (indicados por D1 a D6), de modo a desencadear um processo de não passividade, mas de participação ativa na organização do conhecimento mediado pela TBR, conforme descrição sucinta apresentada nos Quadros 3 e 4, a seguir.

De acordo com a TBR, inicialmente a dimensão do conhecimento Efetivo/Factual é mobilizada contemplando o processo cognitivo 'Lembrar' e 'Entender', em seguida a dimensão 'Conceitual' é incluída perpassando as categorias do processo cognitivo até o 'Avaliar' e culminando na dimensão 'Processual/Procedimental' na categoria 'Criar' com uma única atividade. No Quadro 4, apresenta-se com maiores detalhes a relação das atividades com esse esquema classificatório a partir dos objetivos educacionais. 
Quadro 3 - Níveis trabalhados a partir da análise bidimensional da Taxonomia de Bloom Revisada.

\begin{tabular}{|c|c|c|c|c|c|c|}
\hline \multirow{2}{*}{$\begin{array}{l}\text { Dimensão do } \\
\text { conhecimento }\end{array}$} & \multicolumn{6}{|c|}{ Dimensão do processo cognitivo } \\
\hline & Lembrar & Entender & Aplicar & Analisar & Avaliar & Criar \\
\hline Efetivo/Factual & AT0 & $\begin{array}{c}\text { AT2, AT3 } \\
\text { D1, D2 } \\
\end{array}$ & & & & \\
\hline Conceitual & AT1 & $\begin{array}{c}\text { AT4 } \\
\text { D3, D4 }\end{array}$ & AT5, AT6 & D5 & AT7, AT8 & \\
\hline $\begin{array}{l}\text { Procedimental/ } \\
\text { Procedural }\end{array}$ & & & & & & D6 \\
\hline Metacognitivo & & & & & & \\
\hline
\end{tabular}

Quadro 4 - Atividades elaboradas segundo objetivo educacional.

\begin{tabular}{|c|c|c|}
\hline Atividades & $\begin{array}{l}\text { Conhecimento a ser } \\
\text { adquirido }\end{array}$ & Objetivo educacional \\
\hline AT0 & Concepções prévias & Apontar o conhecimento que o estudante tem sobre a MQ \\
\hline AT1 & Essência da MQ & $\begin{array}{l}\text { Reconhecer as diferenças entre um objeto clássico e um quântico a partir da dualidade } \\
\text { onda-partícula }\end{array}$ \\
\hline AT2 & $\begin{array}{l}\text { Formalismo de Dirac } \\
\text { Processo da criptografia }\end{array}$ & $\begin{array}{l}\text { Reproduzir o formalismo de Dirac através da relação do produto escalar entre dois vetores } \\
\text { Entender a criptografia quântica interpretando o processo de tratamento da informação } \\
\text { quântica }\end{array}$ \\
\hline AT3 & $\begin{array}{l}\text { Limites entre a clássica e a } \\
\text { quântica }\end{array}$ & $\begin{array}{l}\text { Permitir a familiarização com os limites entre a Física Clássica e a MQ através do uso dos } \\
\text { conteúdos fundamentais básicos }\end{array}$ \\
\hline AT4 & $\begin{array}{l}\text { Estudo histórico-conceitual } \\
\text { do Spin }\end{array}$ & $\begin{array}{l}\text { Explorar através da interpretação fenomenológica do experimento Stern-Gerlach a } \\
\text { conceituação do Spin }\end{array}$ \\
\hline AT5 & $\begin{array}{l}\text { Conceitos fundamentais da } \\
\text { MQ }\end{array}$ & Explorar a compreensão conceitual básica dos conteúdos estudados \\
\hline AT6 & (In)completude da MQ & $\begin{array}{l}\text { Demonstrar compreensão histórico-conceitual das implicações teóricas dos paradoxos } \\
\text { propostos }\end{array}$ \\
\hline AT7 & Dinamicidade da Ciência & Reconhecer os processos de construção do conhecimento científico \\
\hline AT8 & Interpretações da MQ & Reconhecer as diferentes interpretações e diferenciá-las \\
\hline D1 & \multirow{5}{*}{$\begin{array}{l}\text { Processo de transposição } \\
\text { didática para o ensino de } \\
\text { MQ no nível médio }\end{array}$} & $\begin{array}{l}\text { Explicar, através da leitura de artigo científico, como tornar possível ensinar conceitos de } \\
\text { MQ no nível médio }\end{array}$ \\
\hline D2 & & $\begin{array}{l}\text { Sumarizar as linhas mestras de artigos científicos que discorram sobre propostas didáticas } \\
\text { de ensinar tópicos de MQ no nível médio }\end{array}$ \\
\hline D3 & & $\begin{array}{l}\text { Inferir sobre quais elementos básicos do formalismo quântico são essenciais ao seu ensino } \\
\text { no nível médio }\end{array}$ \\
\hline D4 & & Inferir sobre quais as estratégias didáticas podem facilitar o ensino da MQ no nível médio \\
\hline D5 & & $\begin{array}{l}\text { Analisar que estrutura conceitual deve ser explorada no ensino médio sendo capaz de } \\
\text { entender a interrelação entre ensino, aprendizagem e importância para sociedade }\end{array}$ \\
\hline D6 & Construção de plano de aula & $\begin{array}{l}\text { Criar um plano de aula elaborando os procedimentos que serão desenvolvidos para } \\
\text { implementar tópicos da MQ no ensino médio }\end{array}$ \\
\hline
\end{tabular}

Em síntese, os objetivos educacionais descrevem o que o estudante necessita realizar para prosseguir com aprendizagem. $\mathrm{O}$ verbo de ação permite definir qual processo cognitivo se espera alcançar. Por sua vez, os enunciados das questões esclarecem como se espera que esse objetivo seja alcançado. As atividades e desafios são do tipo qualitativas com problemas abertos que exigem raciocínio teórico sem necessidade do cálculo numérico (é exceção a AT2 que envolve o formalismo de Dirac). Os desafios têm um caráter de pequenas pesquisas através dos quais os estudantes obtêm respostas por meio de um trabalho prático. É esperado estimular a formulação de hipóteses e chegar a conclusões sobre as características necessárias 
ao ensino da MQ em nível médio e delinear uma estratégia para chegar à 'solução', no caso, estabelecendo seu plano de aula. Portanto, as questões objetivaram, inicialmente, verificar a assimilação dos conceitos de $\mathrm{MQ}$, seguido de interpretação/compreensão, e finalmente, refletir sobre a futura prática docente. $\mathrm{O}$ uso da matemática não foi esquecido durante o curso e foi de muita utilidade para a melhor compreensão dos conceitos quânticos, mas não foi o principal.

\section{Análise e discussão dos resultados}

A percepção de aprendizado através do conhecimento percebido é analisada através da TBR via processo cognitivo (níveis taxonômicos). Foram explorados três níveis de conhecimento: Factual, Conceitual e Processual. Os rendimentos analisados são captados por recortes de escritos e transcrição de trechos importantes da conversação ocorridos durante as aulas. Deve-se ressaltar que na análise dos dados os participantes da pesquisa serão referenciados no texto por Estudante 1, Estudante 2, ..., Estudante 7.

\section{IV.1 Conhecimento Efetivo/Factual}

Esse nível de conhecimento foi percebido através da verificação de concepções prévias (AT0) que explorou o nível do processo cognitivo 'Lembrar'. Em tal atividade, um único item com 7 afirmativas gerais sobre a MQ é designado, através das quais os estudantes devem descrever os conceitos introdutórios que trazem consigo a partir do curso de determinada disciplina. São exemplos de respostas dos estudantes:

"Tem como um dos seus pilares o princípio da incerteza, que revolucionou a maneira de pensar, já que a mecânica clássica que tinha como problema principal definir posição e momento. Logo, a mecânica quântica é baseada em probabilidades, e tendo como particularidade o estudo de partículas pequenas." (Estudante 1)

"Não apenas objetos pequenos, mas sim fenômenos com aspectos 'micro' $e$ 'macro'. Supondo o elétron como partícula e levando em consideração à dualidade onda-partícula, podemos considerar que esse elétron hora é onda, hora é partícula. Podemos fazer uma aproximação de realidade, uma suposição matemática e etc. $O$ objeto de estudo é real." (Estudante 2)

A questão aberta e de caráter bastante amplo abre espaço para o estudante apontar se tinha alguma compreensão a respeito de MQ. Contudo, as respostas para este nível de conhecimento indicam que o 'Conhecimento Factual' percebido foi insatisfatório. Os estudantes não se recordavam dos conceitos quânticos, embora comentassem sobre uma situação no qual tiveram contato com o conteúdo. Os resultados revelam que a apresentação 
de assuntos relativos à Teoria Quântica foi feita de modo tal que os estudantes não reconheceram os conteúdos ou não se apropriaram adequadamente.

Uma possível justificativa para esse resultado é o perfil do curso. Entre os estudantes participantes, apenas um cursou 'Introdução a Mecânica Quântica'. Os demais haviam cursado Física Moderna, que prevê o estudo da Física desenvolvida no século XX, relacionados com a formulação da natureza da matéria em seus aspectos teóricos e experimentais. Nas falas dos estudantes, marca-se outras características que colaboram com nossas observações, como o fato da Física Moderna ser introdutória, a disciplina de MQ não ser obrigatória, pouco tempo destinado a temática ou a didática dos professores ser reduzida a formalismos, que criam obstáculos para o interesse e aprendizado na área.

\footnotetext{
"A quântica aqui não é obrigatória pra licenciatura. Eu mesmo não vou cursar." (Estudante 3)

"A gente cursa moderna e sente apenas o cheiro da quântica." (Estudante 5)

"Um dos maiores problemas que vejo na universidade são os professores bacharéis lecionando nas licenciaturas e que não tem muita metodologia, às vezes, por exemplo para trabalhar com a história da ciência, um bacharel não vai trabalhar com a história da ciência, então vai ser conta mesmo e lista de exercício para responder. Conta sem contexto." (Estudante 6)
}

Constata-se também que a percepção dos estudantes sobre a MQ, inicialmente, era limitada. De suas falas, destacam-se como indícios de comprovação:

"A gente ver os conteúdos de forma resumida. Começou também com Planck e a
radiação do corpo negro, depois o princípio da incerteza. [...], eu lembrei do
experimento que tem, que pode relacionar também com o efeito fotoelétrico por
causa da dualidade da luz e probabilidade [...]". (Estudante 1)
"Lembro bem superficial, estrutura atômica, probabilidade, mas não sei como se
encaixam." (Estudante 3 )

"Não lembro muita coisa da disciplina. Lembro mais ou menos, dos conceitos que a gente viu, começamos com radiação do corpo negro e terminamos com, é, princípio da incerteza. Só que não lembro muita coisa, é algo mais... foi um nível diferente do que eu estava habituado a estudar, então... Achei bem mais dificil, por exemplo de fisica IV eu vi e foi mais fácil, e... Lembro dos exercícios que a gente tinha que fazer, mas correlacionado com isso aqui eu lembro pouca coisa [...]”. (Estudante 2)

Os resultados obtidos para o nível cognitivo 'Lembrar', na sua totalidade, apresentaram insuficiência de domínio do conteúdo básico necessário para o bom desempenho dos estudantes ao longo da proposta didática. Todavia, antecipando-se a esse 
resultado, na reestruturação da proposta didática foram incluídos aspectos gerais e fenomenológicos da MQ afim de estimular maiores rendimentos dos estudantes.

\section{IV.2 Conhecimento Conceitual}

Nessa dimensão, relaciona-se a inter-relação dos elementos básicos num contexto mais elaborado através da síntese do conhecimento factual direcionado ao entendimento das teorias e princípios associados à MQ. Esse nível de conhecimento foi percebido perpassando os níveis do processo cognitivo 'Lembrar' ao 'Avaliar', observando à compreensão conceitual de elementos mais simples da MQ.

A análise dos resultados se dá a partir da AT5, um questionário sobre os conceitos da MQ, com a intenção de verificar como os estudantes conectam o novo conhecimento com o previamente adquirido. Para tal, 12 itens foram propostos dos quais o processo cognitivo mobilizado era o 'Lembrar' (para questões de 1 a 6) e 'Entender' (para questões de 7 a 12) de modo a 'Aplicar' o conteúdo trabalhado. Os quatro primeiros itens da atividade foram retirados do trabalho de Ostermann e Ricci (2004). Ao questionar se existe diferença essencial entre as visões de mundo proporcionadas pela Física Clássica e pela Física Quântica, obtiveram-se respostas como:

\footnotetext{
"Uma trabalha com o micro e a outra trabalha com o macro." (Estudante 1)

"A fisica clássica está mais associada a equações e situações mais 'bem definidas' enquanto a mecânica quântica não nos dá essa certeza. Por exemplo, na clássica podemos prever a partir de um dado inicial ações futuras associadas aquela situação." (Estudante 2)

"Existem diferenças e coisas em comuns entre a física clássica e a MQ. A fisica clássica é determinista e se utiliza do espaço vetorial $r(t)$ para determinar a posição, tempo, velocidade. Já na mecânica quântica é utilizado o operador $|\psi(t)\rangle$ para encontrar o nivel de energia." (Estudante 3)

"A física clássica é deterministica, a quântica probabilística." (Estudante 7)
}

As respostas foram consideradas satisfatórias. Foi evidenciado que os estudantes desenvolveram clareza de que há uma teoria para descrever objetos macroscópicos (Física Clássica) e outra para descrever os objetos microscópicos (MQ). Nos itens 2 e 3, questionamse quais são as propriedades essenciais dos objetos clássicos e quais são as propriedades essenciais dos objetos quânticos. Como resposta, era suficiente listar algumas características dos objetos clássicos e outras dos objetos quânticos. Como exemplo, segue a resposta do Estudante 2:

\footnotetext{
"Varia com a situação. Por exemplo ao estudar o M.R.U e descrevê-lo precisamos de ao menos duas informações a depender de "onde queremos" chegar; precisamos
} 
do tempo, espaço, velocidade etc. quaisquer duas informações poderá nos dar a possibilidade de efetuar medidas. [...] Na mecânica quântica, diferentemente da clássica não podemos (eu acho) associar o que seria essencial, pois um mesmo parâmetro inicial estudado mais de uma vez, poderá mostrar resultados diferentes, sendo assim, o que viria ser essencial?"

Percebe-se imprecisões na compreensão dos aspectos essenciais da MQ, fazendo inclusive confusão interpretativa. Ainda, questionou-se (item 4) qual é a principal diferença entre objetos clássicos e objetos quânticos. Algumas respostas:

"Na clássica são usadas equações deterministicas para definir o movimento de um objeto. Na mecânica quântica utiliza-se de operadores probabilísticos." (Estudante 2)

"Os objetos clássicos estão associados aos objetos macroscópicos e a quântica associada ao micro." (Estudante 3)

"Um objeto clássico sempre se comportará da mesma forma estando em condições iguais. O mesmo não acontece com um objeto quântico que está numa superposição de estados possiveis." (Estudante 7)

Nessa questão, características foram apontadas corretamente, embora não se tenha menção ao Princípio da Incerteza ou Dualidade onda-partícula. Ao se questionar (item 5), em específico, sobre a experiência dupla-fenda: um feixe de elétrons passa por duas fendas e forma um padrão de interferência numa tela cintiladora. O que acontece quando apenas 1 elétron passa pelas fendas, retirada de Montenegro, Pessoa Jr. (2002) - tem-se:

\footnotetext{
“A cintilação será em um ponto." (Estudante 1)

"Ao passar apenas um elétron podemos observar um fenômeno diferente, pois agora ele se comporta como partícula, não como onda." (Estudante 2)

"Ele passará ao mesmo tempo por ambas as fendas e interagirá consigo mesmo gerando um padrão de interferência. Mas se for colocado um aparelho de medida nas fendas para ver por onde o elétron passou, ele deixa de se comportar como onda e passa a se comportar como partícula, não mais formando um padrão de interferência." (Estudante 7)
}

Para os estudantes 1 e 2, percebe-se a inclusão da visão corpuscular clássica (salienta que ocorre uma detecção pontual). Segundo Montenegro e Pessoa Jr. (2002, p. 111), uma resposta esperada é "que haveria apenas uma cintilação pontual na tela, sem a formação de um padrão espacialmente estendido". Já o estudante 7 indica características ondulatória. Sabese que há na literatura científica diversas interpretações para a teoria quântica. Sua essência é a dualidade onda-partícula conforme ressaltado por Pessoa Jr. (2003, p. 1): "é a teoria que atribui, para qualquer partícula individual, aspectos ondulatórios, e para qualquer forma de 
radiação, aspectos corpusculares. Esta é uma versão "geral" da dualidade onda-partícula". As respostas dos estudantes passam a indicar interpretações. Semelhantemente, observa-se compreensão de princípios e conceitos básicos da teoria quântica como, por exemplo, sobre o Princípio de Incerteza ou a probabilidade, evidenciado a partir das respostas da Questão 6:

\footnotetext{
"É impossivel medir, no mesmo instante, com precisão ilimitada, a posição e a quantidade de movimento de uma partícula e, consequentemente, sua velocidade." (Estudante 1)

"Um exemplo mais comum é a do gato que está dentro de uma caixa, onde ao abrila o gato poderá estar vivo ou morto. Isto é um evento probabilístico." (Estudante 3)
}

Para o segundo bloco de questões (7 a 12), o processo cognitivo 'Entender' não foi alcançado. Os estudantes não conseguiram dissertar sobre os postulados da MQ, nem explicitar noções básicas sobre o formalismo matemático. É importante ressaltar que a linguagem matemática da notação de Dirac apresentada aos estudantes foi oportunizada de modo a configurar um primeiro contato e não com a necessidade de maior aprofundamento. $\mathrm{O}$ cuidado ao desenvolver a proposta foi de não negligenciar os aspectos conceituais e interpretativos. Portanto, considerou-se positivo os estudantes tentarem responder as questões propostas conforme relata o estudante 2: "Depois fui fazer as questões sobre o formalismo de Dirac, mas tive dificuldade nessa última questão".

Toda a parte inicial do curso foi estrategicamente pensada em oferecer os conhecimentos necessários para uma melhor discussão do contexto histórico que seria discutido. No entanto, verificou-se oscilações no interesse e motivação dos estudantes. Mesmo se tratando de uma proposta inovadora, a inclusão da discussão conceitual e do formalismo (sem excessos) é necessária, uma vez que o conhecimento Efetivo/Factual dos estudantes sobre esses aspectos era insuficiente, conforme analisado anteriormente.

Em paralelo às escolhas didáticas, um aspecto negativo muito marcante foi a falta de dedicação dos estudantes. A professora-pesquisadora questionava-os acerca da realização das atividades e, em alguns momentos, os mesmos reconheciam as lacunas que iam deixando pelo caminho, como é demonstrado pela fala do Estudante 3: "Na verdade, deixei para fazer com pouco tempo, eu devia ter sentado, refletido. Fui irresponsável em relação a isso." Nesse caso, atividades que deveriam auxiliar os estudantes no aprendizado não cumpriram seu papel. Aos que faziam as atividades, ainda que incompletas, foi possível verificar progressos na compreensão conceitual.

Ainda, com a intenção de auxiliar no processo de concepção fenomenológica dos estudantes, foram inseridos no material de apoio três simulações computacionais sobre a Experiência da Dupla-Fenda, Criptografia Quântica e Emaranhamento Quântico. No entanto, a eficácia desse recurso esbarrou na falta de familiaridade com uso de simulações, como 
sinaliza o estudante 3: "Eu baixei o programa do phet, vi o comportamento, mas não entendi o que era pra fazer. Não compreendi [...]"

Do ponto de vista didático, as ferramentas adotadas para o ensino tornam-se cruciais para a assimilação das informações pelo estudante. Assim, a utilização diversificada de ferramentas educacionais aponta para uma aprendizagem dinâmica e, no contexto vivenciado, sendo apoiada pela HFC. Logo, a falta dessa percepção nos processos formativos prejudicou o processo aqui proposto, uma vez que, possivelmente, eles não percebam a relevância desses recursos para sua aprendizagem.

Os resultados do primeiro momento da proposta didática revelam que o objetivo educacional de promover a compreensão conceitual básica dos conteúdos estudados foi parcialmente alcançado. Houve progresso no modo como o conteúdo foi conduzido e recebido pelos estudantes com indícios de uma familiarização com os conceitos quânticos. As dimensões do conhecimento Efetivo/Factual e o conhecimento Conceitual foram progressivamente alcançadas, embora se reconheça não ser em nível ideal.

$\mathrm{Na}$ sequência dos encontros, houve o aprofundamento conceitual da MQ através da abordagem histórica avançando de acordo com o processo cognitivo. Os estudantes são apresentados a textos que contém trechos dos originais com os quais se investe na discussão da (in)completude da MQ, abandono do determinismo e o reconhecimento da não-localidade. Para que possam interpretá-los adequadamente, os discentes precisariam 'Aplicar' o conhecimento conceitual adquirido e 'Avaliar' sua aplicação em novos contextos. Com recortes dos textos de Einstein et al. (1935) e Schrödinger (1935), foram apresentados os experimentos de pensamento de EPR e do gato de Schrödinger.

Para verificar o entendimento dos estudantes sobre as consequências epistemológicas destes para o contínuo desenvolvimento da Teoria Quântica, o primeiro questionamento envolveu a questão da incompletude da teoria. De suas falas, tem-se:

\footnotetext{
"Os experimentos de pensamento tinham um caráter contra intuitivo e tentava salvar o determinismo. Essa parte eles vão focar muito na parte da trajetória das partículas. Eles trazem uma visão da física clássica de tentar determinar, então significa que uma teoria completa é aquela que abrange tudo. Porque com o determinismo eu consigo medir tudo, então é uma teoria completa. E ao longo do texto eles sempre vai falando as condições para a MQ está completa. Então, consequentemente, a MQ não conseguiria prever a realidade já que antes da observação a medida era por probabilidade." (Estudante 1)

"EPR tentava salvar o determinismo falando que a Mecânica Quântica está incompleta." (Estudante 3)

"A partir do experimento EPR, foi-se deduzindo que poderia se conhecer o estado de um sistema sem efetuar o ato de medir, ..., mas isto deu espaço para que o paradoxo fosse solucionado a partir do entrelaçamento dos subestados de um sistema completo. " (Estudante 4)
} 
Nesse momento do curso, os estudantes já haviam desenvolvido a compreensão de que a Teoria Quântica admite uma solução probabilista, o que facilitou a abordagem histórica dos trabalhos de Einstein et al. (1935) e Schrödinger (1935). Com clareza os estudantes falam: "Os experimentos de pensamento tinham um caráter contra intuitivo e tentava salvar o determinismo" - Estudante 1; "EPR tentava salvar o determinismo falando que a Mecânica Quântica está incompleta" - Estudante 3. Com isso, a mediação segue para discutir o determinismo clássico e o indeterminismo e como entrara em choque no desenvolvimento da teoria. Também foi discutido o princípio da superposição e a relação com o gato de Schrödinger, levando os estudantes a argumentarem sobre o que representa o determinismo para a Física nesse contexto de discussão:

\section{“Características definidas, posição, momentum." (Estudante 3) \\ "Na visão deles a MQ não está completa, então eles tentam completar com argumentos determinísticos que não são tão bem desenvolvidos, que no próprio texto que se inicia com perguntas, e se termina sem respostas. E dai tem a proposta de Schrödinger que vai contra a parte determinística do EPR, mas por lado positivo, mostra que tem preocupação ainda com a MQ, então mostra que é uma teoria que está evoluindo e não está completa. Mas sim sendo adequada a cada dia." (Estudante 1)}

$\mathrm{Na}$ sequência, para que os estudantes conhecessem a Teoria de Variáveis Ocultas através das Desigualdades de Bell, trechos do texto de Bell (1964) foram apresentados. Sobre este assunto, os estudantes declaram:

\footnotetext{
"Essas variáveis adicionais vêm com a obrigatoriedade de respaldar a questão da localidade e realidade. [...] Em relação a localidade que tem a ver com a questão de nenhum objeto no universo sobrepor a velocidade da luz e etc, ai esse negócio lá de Einstein da ação fantasmagórica onde você tem duas partículas e você pega uma e coloca uma lá nos confins do universo e quando você mexe uma a outra instantaneamente ela percebe, então questiona a velocidade e mexe com a questão da localidade." (Estudante 5)
}

"Bell queria verificar se essas coisas do realismo e localidade através das variáveis ocultas era verdadeira ou não. Ainda achei no texto que até Bell também acreditava na localidade e realidade. Então ele foi verificar e percebeu não como spin baixo/cima, mas ele percebeu que essas variações de posições dos elétrons estavam associadas a uma função relacionada ao ângulo deles. Uma coisa assim." (Estudante 2)

Prosseguindo a discussão, os estudantes percebem as chamadas Desigualdades de Bell como mais uma tentativa de salvar o determinismo clássico, explicitado na fala do Estudante 2: "até Bell também acreditava na localidade e realidade". Na mesma aula, os estudantes discutem corretamente como o experimento de Aspect elucidou o argumento de 
EPR destacando que a hipótese do realismo local, no que diz respeito à MQ, é recusada e como influencia algumas interpretações dos fenômenos quânticos.

Em termos gerais, trazendo essas concepções para a prática desenvolvida, foi percebido alguns desafios com o uso da HFC como o eixo condutor do ensino. Não há cultura de leitura prévia por parte dos estudantes para presenciar uma aula. Eles estão mais habituados a assistir aula e responder exercícios, e novamente se percebe a falta de dedicação. Apesar disso, verificou-se que o índice de satisfação da maioria dos estudantes em relação à definição dos objetivos educacionais foi positivo.

A curiosidade quanto aplicações da MQ esteve sempre presente, bem como foi percebido interesse nas interpretações. Conclui-se, portanto, que os conhecimentos oportunizados durante o curso, de modo geral, aumentou o potencial de compreensão dos estudantes. $\mathrm{O}$ acesso ao conhecimento, conforme estruturado, parece ter contribuído para mudança do cenário, demostrando a possibilidade de se apresentar a teoria de maneira mais próxima à linguagem dos estudantes.

\section{IV.3 Conhecimento Procedimental/Procedural}

Por último, é proposto que os estudantes utilizem o conhecimento do conteúdo e as habilidades intelectuais adquiridas no ambiente acadêmico para elaborar um plano de aula. É mobilizado o processo cognitivo 'Criar' com intenção de que percebam possibilidades para ensinar MQ no nível médio via o processo de transposição didática.

Esse processo de criação envolveu o desenvolvimento de ideias, métodos e procedimentos, o que proporcionou aos estudantes, entre outros aspectos, uma percepção da interdisciplinaridade entre os conceitos científicos e a importância dos assuntos de ordem didático-pedagógicos para a futura prática docente. Os estudantes assumem o papel direto de agentes ativos, capazes de 'Aplicar' o conhecimento quando postos em situação de futuro professor. Em primeira instância, os estudantes realizaram julgamentos em termos de conteúdo e de como escolher referências e materiais didáticos. Observou-se um processo de (des)confiança das fontes de busca, por exemplo:

\footnotetext{
"Peguei vários artigos. Eu achei bacana, porque a gente acha tão dificil e quando pega o artigo eles aplicam de uma forma tão simples, você fica, isso não vai funcionar não. Mas ao ver os resultados no final do artigo, você fala poxa, teve um feedback positivo. Então dar não só embasamento, mas também coragem para tentar inovar em sala de aula." (Estudante 1)
}

Processualmente, os estudantes desenvolvem habilidades necessárias a formação docente, tendo em mente que preparar aula não é algo trivial. Em consequência, revelam uma preocupação com o ensino de MQ, tanto com a complexidade da teoria como com o processo de transposição didática para não recair em simplificações exageradas: 


\begin{abstract}
"Mais assim, um dos problemas é justamente utilizar as equações matemáticas e principalmente os pré-requisitos também, né? O problema é que os alunos do ensino médio, eles não têm uma base tão fundamentada na matemática, além de outros problemas como a estrutura da escola, os professores. A questão da formação do professor e como deve abordar, e ai trabalhando principalmente com a questão mais teórica, fundamentada, questão histórica, epistemologia. E mostrar também os modelos, trabalhar com a modelagem para que os alunos possam entender minimamente a estrutura." (Estudante 3)
\end{abstract}

"Não basta saber o que tem que fazer, mas precisamos saber o como fazer." (Estudante 5)

"Eu acho que a primeira coisa é dominar o que se quer ensinar. Ninguém sobe em um palco e assume o lugar do baterista sem ser baterista. Ai eu vou ensinar MQ sem saber, não dá." (Estudante 7)

Destarte, o ato de levar o futuro professor a refletir sobre ações voltadas para articular os saberes específicos com as novas exigências para o ensino e reformas educacionais oriundas das regulamentações brasileiras é visto como positivo e necessário (MORAN et al., 2013). É levado em consideração a necessidade de integração entre saberes específicos de que tratam a recente Base Nacional Comum Curricular para o ensino médio (BRASIL, 2018). Dessa maneira, o futuro professor deve refletir sobre algumas mudanças inerentes à própria gestão do conhecimento.

A análise dos planos de aula $(n=5)$ mostram que os estudantes têm uma concepção de ensino de Física ainda com um caráter extremamente conteudista e fragmentado, muito próximo aos esquemas tradicionais. Um problema que se observa é um distanciamento da pergunta "para que serve". Falta uma atenção para a discussão da funcionalidade física do conteúdo ministrado - aspectos que contribuirá também para a formação mais ampla no nível médio. Assim, considerou-se urgente o pensar em aulas mais inovadores, onde haja diminuição de um academicismo distante da realidade atual. É preciso um ensino de Física como estudo da natureza vinculada da ação humana (SCHEID, 2018).

\title{
IV.4 Reflexão sobre a ação
}

Pode-se afirmar, em termos gerais da TBR, que o nível cognitivo mais estimulado e percebido foi 'Analisar'. De acordo com os resultados da pesquisa, a composição de apresentar os conceitos fundamentais da MQ e, em seguida, discutir conceitos específicos por meio da contextualização histórica foi o aspecto mais influente da proposta didática. Foi percebido um nível satisfatório de conhecimento. Os estudantes avançaram em aprendizagem, inclusive desenvolvendo a capacidade de relacionar o conteúdo com a prática. A discussão da (in)completude da MQ e do abandono do determinismo por meio da HFC estimulou este aspecto cognitivo de forma a refletirem sobre a construção do conhecimento científico. 
No entanto, a condução do trabalho em sala de aula enfrentou desafios relacionados à passividade dos estudantes guiados por um método centrado no professor, embora que oportunizasse a contextualização histórica dos conteúdos e sua aplicabilidade voltada para a aproximação com a prática docente. Reconheceu-se a não centralização das dificuldades enfrentadas, pura e simplesmente, ao estudante.

O esperado era um processo de ensino destoante do formal, no qual os estudantes fossem auxiliados no aprender, que fossem o centro da atenção e participante ativo visto, também, como pessoa em desenvolvimento. Nas aulas deveria haver uma orientação coletiva, enquanto, que em casa, os estudantes deveriam seguir os estudos com experiências variadas oportunizadas por leitura/interpretação de textos, uso de simulação computacional, atividades de aprendizagem etc. Para tal, o material de apoio elaborado foi pensado de modo a ser meio para o desenvolvimento do estudante que permitisse a assimilação do conteúdo, tendo o professor como orientador desse processo.

Ainda, marcou-se uma linha tênue entre uma didática que prioriza o ensino (via transmissor de conhecimentos) e as recentes argumentações que priorizam a orientação do aprendizado. Inferiu-se que esse quadro foi reflexo de uma formação da professorapesquisadora carregada de tradicionalismo e distante das ideias de Vigotski. Por exemplo, o silêncio dos estudantes, interpretado como não compreensão, era seguido de nova explicação, mas sem um novo questionamento. A professora, recaia em cumprir o programa e, consequentemente, por ter uma carga horária reduzida limitava a interação com os estudantes devido ao desejo por adequação ao planejamento.

Outros aspectos geradores de dificuldades dizem respeito aos objetivos da proposta que deveriam ter sido menos ambiciosos e ao próprio conteúdo escolhido que não se trata de um tema constantemente ensinado. Os estudantes não conheciam o formalismo adotado e tinham sérias limitações de bases conceituais. Seja por falta de dedicação dos estudantes, ação da professora ou por número limitado de aulas, a forma de abordagem não foi suficiente em sua totalidade, ainda que a HFC marque contribuições para o avanço na compreensão conceitual de aspectos intrínsecos da MQ.

A abordagem proposta contribuiu para que os estudantes fossem convidados a ler, discutir assuntos, refletir e dar sua opinião, ajudando ativamente no processo de aprendizagem. Isso resultou no desenvolvimento de boas noções de como a MQ se consolidou no início do século passado e de como por mais de 100 anos continua se desenvolvendo. A HFC, portanto, auxilia nesse quesito, e aqui foi destacada a maior contribuição da proposta didática implementada. Foi possível perceber a desenvoltura de determinadas habilidades, atitudes e capacidades dos estudantes, bem como um interesse para a ênfase na aplicação prática do conteúdo específico. 


\section{Considerações Finais}

Nessa pesquisa as aulas pautadas pela HFC no ensino de MQ demonstram a possibilidade de avançar no rendimento dos estudantes tendo em vista seus diversos comentários positivos, bem como as respostas obtidas nas atividades propostas. Apontam também, todavia, uma deficiência, em particular, quanto à dedicação dos estudantes ao processo de ensino-aprendizagem e postura adotada pela professora-pesquisadora.

Algumas falhas foram percebidas pela professora-pesquisadora: limite de 10 encontros (20 aulas) para discussão de grande quantidade de conteúdo; calendário apertado para cumprimento da ementa da disciplina; excesso de objetivos a serem alcançados, principalmente porque do tempo disposto para implementação. Esses constituem pontos de melhorias para futuras aplicações.

Contudo, os benefícios providos pela contextualização histórica são visíveis e se estendem quanto à prática docente. A abordagem se mostra adequada quanto à sua flexibilidade e articulação das ações pedagógicas. Os resultados revelam uma percepção satisfatória de conhecimento adquirido, verificando a preocupação dos futuros professores com o aprender/ensinar MQ. Com destaque à dimensão cognitiva 'Analisar' que teve maior fator de impacto.

Entre as principais características que valorizam essa prática, foram encontradas: 1) A importância de ser criativo e de buscar sempre as novidades para o despertar da curiosidade e, portanto, alcançar o objetivo educacional; 2) A HFC como o eixo condutor do ensino permitiu um nível de conhecimento percebido, satisfatório e proveitoso. Houve melhor compreensão de tópicos relacionados à teoria quântica; 3) $\mathrm{O}$ uso didático da HFC permite a discussão de contextos históricos em que cada conceito foi proposto, bem como uma ampla análise das implicações epistemológicas dos sujeitos envolvidos na construção do conceito, o que promove visões não reducionistas da ciência; 4) $\mathrm{O}$ material de apoio disponibilizado agregou fontes primárias e secundárias em sua constituição, o que permitiu uma visão mais consistente do papel dos cientistas no fazer científico e entendimento das diversas estratégias comunicativas presentes nos trabalhos científicos para a construção de conhecimento; 5) A avaliação foi condizente com o curso proposto, exigindo um nível de conhecimento cognitivo adequado ao estágio de desenvolvimento do estudante.

Por fim, a construção de propostas didáticas, como a deste trabalho, mostra-se como item de grande importância para suprir a lacuna existente entre reconhecer os benefícios do uso didático da HFC e persegui-los efetivamente na prática docente. Do ponto de vista curricular, estimula-se a reformulação e inovação do processo de ensino-aprendizagem de maneira mais significativa, bem como se espera que essas atividades sejam utilizadas por outros pesquisadores e professores, contribuindo para o surgimento de novas ideias. 


\section{Agradecimento}

Agradecemos a Coordenação de Aperfeiçoamento de Pessoal de Nível Superior (CAPES) pelo auxílio financeiro para realização dessa pesquisa.

\section{Referências bibliográficas}

ALBERT, D. Z. Quantum Mechanics and experience. Harvard University Press, 1994. p. 206.

ANDERSON, L. W.; KRATHWOHL, D. R. A taxonomy for learning, teaching, and assessing: A revision of Bloom's taxonomy of educational objectives. [S.1.]: Allyn \& Bacon, 2001.

ARTIGUE, M. Didactical engeneering as a framework for the conception of teaching products. In: BIEHLER, R. E. A. (Ed.). Didactics of Mathematics as a Scientific Discipline. Netherlands: Kluwer Academic Publishers, p. 27-39, 1994.

ASPECT, A.; DALIBARD, J.; ROGER, G. Experimental test of Bell's inequalities using time-varying analyzers. Physical Review Letters, v. 49, n. 25, p. 1804-1807, 1982 b.

BRASIL. Base Nacional Comum Curricular (BNCC). Educação é a Base. Brasília, MEC/CONSED/UNDIME, 2018. Disponível em:

$<$ http://basenacionalcomum.mec.gov.br/images/BNCC_EI_EF_110518_versaofinal_site.pdf $>$ Acesso em: 30 de Jul. 2020.

BELL, J. S. On the Einstein Podolsky Rosen Paradox. Physics 1, p. 195-200, 1964.

BROCKINGTON, G.; PIETROCOLA, M. Serão as regras da transposição didática aplicáveis à Física Moderna? Investigações em Ensino de Ciências, v. 10, n. 3, p. 387-404, 2005.

CHEVALLARD, Y. La transposición didáctica: del saber sabio al saber enseñado. La Pensée Sauvage, Argentina, 1991.

COLL, C. et al. Los contenidos en la reforma: enseñanza y aprendizaje de conceptos, procedimientos y actitudes. Buenos Aires, 1992.

CUESTA-BELTRÁN, Y. J. Estado del arte: tendências en la enseñanza de la física cuántica entre 1986 y 2016. TED: $\mathrm{N}^{\circ}$ 44, p. 147-166, 2018. 
DIDIŞ, N.; ERYILMAZ, A.; ERKOÇ, Ş. Pre-service Physics Teachers'Comprehension of Quantum Mechanical Concepts. Eurasia Journal of Mathematics, Science \& Technology Education, v. 6, n. 4, p. 227-235, 2010.

EINSTEIN, A.; PODOLSKY, B.; ROSEN, N. Can quantum-mechanical description of physical reality be considered complete? Physical Review, v. 47, p. 777-780, 1935.

FORATO, T. C. M.; MARTINS, R. A.; PIETROCOLA, M. Temas de História e Filosofia da Ciência no Ensino. In: PEDUZZI, L. O. Q.; MARTINS, A. F. P; FERREIRA, J. M. H. (Orgs.) EDUFRN, Natal, 2012. p.123-154.

GIL PÉREZ. D. el al. Para uma imagem não deformada do trabalho científico. Ciência \& Educação, v. 7, n. 2, p. 125-153; 2001.

GRECA, I. M. Construindo significados em mecânica quântica: resultados de uma proposta didática aplicada a estudantes de física geral. 2000. Tese (Doutorado em Física) Universidade Federal do Rio Grande do Sul, Porto Alegre.

HÖTTECKE, D.; HENKE, A.; RIESS, F. Implementing History and Philosophy in Science Teaching: Strategies, Methods, Results and Experiences from the European HIPST Project. Science \& Education, v. 21, p. 1233, 2010.

JOHANSSON, A. et al. "Shut up and calculate": the available discursive positions in quantum physics courses. Cultural Studies of Science Education, v. 13, p. 205-226, 2016.

KAMPOURAKIS, K. The "general aspects" conceptualization as a pragmatic and effective means to introducing students to nature of science. Journal of Research in Science Teaching, v. 53, p. 667-682, 2016.

MARTINS, A. F. P. História e filosofia da ciência no ensino: Há muitas pedras nesse caminho. Caderno Brasileiro do Ensino de Física, v. 24, n. 1, p. 112-131, 2007.

MARTINS, A. F. P. Natureza da Ciência no ensino de ciências: uma proposta baseada em "temas" e "questões". Caderno Brasileiro de Ensino de Física, v. 32, n. 3, p. 703-737, dez. 2015.

MARTINS, R. A. Sobre o papel da história da ciência no ensino. Boletim da Sociedade Brasileira de História da Ciência, n. 9, p. 3-5, 1990. 
MATTHEWS, M. Science Teaching: The Role of History and Philosophy of Science. New York: Routledge. 1994.

MATTHEWS, M. História, Filosofia e Ensino de Ciências: a tendência atual de reaproximação. Caderno Catarinense de Ensino de Física, v.12, n. 3, p. 164-214, 1995.

MODY, C. C. M. Scientific Practice and Science Education. Science Education, v. 99, n. 6, p. 1026-1032, 2015.

MORAN, J. M.; MASETTO, M. T.; BEHRENS, M. A. Novas tecnologias e mediação pedagógica. 21. ed. Campinas: Papirus, 2013.

MONTENEGRO, R. L.; PESSOA JR., O. Interpretações da Teoria Quântica e as concepções dos estudantes do curso de Física. Investigações em Ensino de Ciências, v. 7, n. 2, p. 107126, 2002.

MOURA, B. A.; SILVA, C. C. Critical and Transformative Teachers: A Rationale for History and Philosophy of Science in Teacher Education. In: PRESTES, M. E. B.; SILVA, C. C. (Eds.). Teaching Science with Context: Historical, Philosophical, and Sociological Approaches. 2. ed. São Paulo: Saraiva, 2018. cap.1. p. 3-13.

MOURA, C. B., GUERRA, A. História cultural da ciência: um caminho possível para a discussão sobre as práticas científicas no ensino de ciências? Revista Brasileira de Pesquisa em Educação em Ciências, v. 16, n. 3, p. 725-748, 2016.

MÜLLER, R.; WIESNER, H. Teaching quantum mechanics on an introductory level. American Journal of Physics, v. 70, n. 3, p. 200-209, 2002.

NETTO, J. S. Complementaridade onda-partícula e emaranhamento quântico na formação de professores de Física segundo a perspectiva sociocultural. 2015. $311 \mathrm{f}$. (Doutorado) - Programa de Pós-Graduação em Ensino de Física, Instituto de Física, Universidade Federal do Rio Grande do Sul, Porto Alegre.

NUNES, A. L. Física Quântica para Todos. In: SIMPÓSIO NACIONAL DE ENSINO DE FÍSICA, XVII, 2007. Atas...

OLIVEIRA, I. S. et al. Emaranhamento Quântico. Ciência Hoje, v. 42, n. 249, p. 32, 2008. 
OliVEIRA, R. A.; SILVA, A. P. B. Temas de História e Filosofia da Ciência no Ensino. In: PEDUZZI, L. O. Q.; MARTINS, A. F. P; FERREIRA, J. M. H. (Orgs.) EDUFRN, Natal, 2012. p. 41-64.

OSTERMANN, F.; RICCI, T. S. F. Construindo uma unidade didática conceitual sobre Mecânica Quântica: um estudo na formação de professores de Física. Ciência \& Educação, v. 2, p. 235-258, 2004.

PESSOA JR, O. Conceitos de Física Quântica. São Paulo: Livraria da Física, 2003.

PESSOA JR., O. Introdução histórica à Teoria Quântica, aos seus problemas de fundamento e às suas interpretações. Caderno de Física da UEFS, v. 04, n. 01 e 02, p. 89-114, 2006.

PRESTES, M. E. B.; CALDEIRA, A. M. A. Introdução. A importância da história da ciência na educação científica. Filosofia e História da Biologia, v. 4, p. 1-16, 2009.

PIQUEIRA, J. R. C. Teoria quântica da informação: impossibilidade de cópia, entrelaçamento e teletransporte. Revista Brasileira de Ensino de Física, v. 33, n. 4, p. 4303, 2011.

RIGOLIN, G.; RIEZNIK, A. A. Introdução à criptografia quântica. Revista Brasileira de Ensino de Física, v. 27, n. 4, p. 517-526, 2005.

ROSALES, S. F. D.; VERGARA, J. R. A.; VELEZ, E. L. M. ?Qué sentido tiene la naturaleza de la ciencia y la historiade la ciencia en la formación ciudadana y valórica de un ser planetário? In: GATICA, M. Q.; ROSALES, S. D.; CASTILlO, H. C. (Orgs.). Historia y Filosofía de la ciencia: aportes pra uma 'nueva aula de ciencias', promotora de cidadania y valores. Santiago do Chile: Bellaterra, 2014

SCHEID, N. M. J. História da ciência na educação científica e tecnológica: contribuições e desafios. Revista brasileira de Ensino em Ciência e Tecnologia, Ponta Grossa, v. 11, n. 2, p. 443-458, 2018.

SILVA, B. V. C. História e filosofia da ciência como subsídio para elaborar estratégias didáticas em sala de aula: um relato de experiência em sala de aula. Revista Ciência \& Ideias, v. 3, n. 2, 2012.

SOUZA, R. S.; SILVA, I.; TEIXEIRA, E. S. Conceitos de Física Quântica na formação de professores: construindo uma proposta didática orientada pela História e Filosofia da Ciência. In: SNHCT, 16, 2018. Anais eletrônicos... ISBN: 978-85-93331-02-2, 2018. 
SOUZA, R. S.; SILVA, I.; TEIXEIRA, E. S. Contextualização histórica dos conceitos de emaranhamento quântico e não-localidade. Revista Docência do Ensino Superior, v. 10, p. 1-20, 13 jul. 2020.

SOUZA, R. S.; GRECA, I. M.; SILVA, I.; TEIXEIRA, E.S. Reflexões sobre o Ensino de Mecânica Quântica nos Cursos de Graduação em Física a partir de Revisão Sistemática. Revista Brasileira de Pesquisa em Educação em Ciências, v. 20, p. 1363-1391, 2021.

VIGOTSKI, L. S. Psicologia pedagógica. Porto Alegre: Artmed, 2003. (Trabalho original publicado em 1926) 